\section{4b PREVENTION PAYS! EVIDENCE FROM FRANCE}

Paul Duphil. OPPBTP, Boulogne Billancourt, France

\subsection{6/oemed-2018-ICOHabstracts.241}

Objectives The cost of prevention is often taken as an excuse for not acting or not fully implementing all required measures for effective OSH. Prevention is often presented as a matter of regulation and obligations, and the economic return of prevention actions is rarely studied. Based on field studies and experience, OPPBTP demonstrates with more than 200 practical cases that prevention pays, with an average ROI of 2.33. Online tools are being developed to facilitate the practice with construction management.

Methods OPPBTP developed a business case study, with accounting techniques. The methodology enables to identify all the operational impacts of the studied cases, short and long term, whether beneficial for productivity, quality, business activity, and to quantify them in term of financial impact. High interest from major French construction companies led OPPBTP to develop both training tools to transfer the knowhow to a large population of OSH experts, and develop an online tool for case calculation. CPWR developed similar cases and tools. CPWR developed as well ROI calculation tools, based on standard US accounting standards.

Results More than 200 specific prevention cases, ranging from new equipment to training schemes or process improvement projects have been studied, showing an average return on investment equal to 2.33! Moreover, the work and its methodology enable $\mathrm{OSH}$ experts to include prevention action within the business logic that is first and foremost in private companies, and develop new arguments to convince managers and workers alike that prevention and production go hand in hand.

Conclusion Prevention pays! This popular motto among $\mathrm{OSH}$ experts needs to be demonstrated in a simple and convincing manner for frontline managers, and adequate tools be made available to them. This approach is complementary to existing academic studies that tend to demonstrate the same results, however addressing a different public. This study enabled not only to bring proof about the positive economic return of prevention, but it enabled to change the way companies look at prevention, and the way preventors look at economics. This is a very interesting finding of our studies.

\section{C VISION ZERO FROM AN EMERGING ECONOMY PERSPECTIVE}

Krishna Nirmalya. Larsen and Toubro Limited, Chennai, India

\subsection{6/oemed-2018-ICOHabstracts.242}

Changes in business narratives have been at pace, during the last few decades. Improved corporate governance, shift of focus from traditional economic performance to GRI mandated economic, environmental and social performances, commonly referred as 'triple bottom line' have brought perspective changes in the corporate world, globally.

While sharp awareness and concerted efforts on environmental front keep on gathering steam, it has become significant to substantiate and support the need to protect the people from the sources of immediate and acute harm. This is, in a way, influencing the alignment and advancement of 'VISION ZERO' with far reaching positive consequences across the industrial and service sectors, obviously in varying degrees.

Study of 'Sustainability reports' of the organisational journey have shown significant differences within various sectors and across the enterprises, mostly driven by strong leadership commitments towards HSE. These organisations have tracked the journey in tandem with business objectives and goals, while some of the entities displayed the need of granting more time and support to catch-up.

Construction industry, which contributes around $7 \%$ to $10 \%$ of GDP, is among the most risky businesses as per several studies across the globe. Emerging economies with increasingly higher share of GDP, have registered enhanced contribution of incident and injuries.

Several challenges, including demographics and infrastructure related aspects, spanning from organisational factors to people related issues, impact the journey. At micro levels, local management, equipment and crew, fitness and suitability of all for the specific worksites, hugely matters.

Journey forward for higher level of achievement shall naturally be dependent on multiple factor, primarily though on sustained leadership from government, industry and labour organisations.

\section{4d DIAGNEO: A PRACTICAL TOOL FOR SMES TO IMPLEMENT VISION ZERO}

Jean-Claude Poirier. CRAMIF, Paris, France

\subsection{6/oemed-2018-ICOHabstracts.243}

The company owner or manager must be the driver of the implementation of a culture on prevention in order to develop sustainable work and a sense of well-being at work among their employees. But, most employers in the construction industry are small or medium size employers (SMEs). They have limited resources, including safety and health expertise. They also typically are the highest risk employers. How can we assist them in improving their safety and health performance?

Vision Zero is very practical approach to improving safety, by focusing only on the seven Golden Rules. In France, we have developed an online platform that employers can use to self-assess their safety performance. It is known as DIAGNEO, and is compatible with Vision Zero.

DIAGNEO was developed with minimal resources and has been validated by safety and health experts in collaboration with employers in the construction industry and is currently available to over 200000 construction employers in the Paris region, free of charge. It is easy to use, and does not take a lot of time to complete.

After answers to several questionnaires, a profile of probable safety and health performance appears immediately in the form of graphics, which allows the employer to easily understand its deficiencies and where its priorities on regulatory, organisational and technical actions need to be placed.

The examination of specific risks to the workplace and exposures is a prerequisite for the prevention of occupational risks. DIAGNEO makes it feasible to do so for even very small and resource-poor employers. There is no longer any excuse for employers not to undertake a self-assessment on Safety and Health at Work. 